\title{
Enhanced Oil Recovery by Cyclic Injection of Wettability Alteration Agent for Tight Reservoirs
}

\author{
Zhijie Wei $\mathbb{D}^{1,2}$ Yuyang Liu $\mathbb{D}^{1,2}$ and Xiaodong Kang ${ }^{1,2}$ \\ ${ }^{1}$ State Key Laboratory of Offshore Oil Exploitation, Beijing 100028, China \\ ${ }^{2}$ CNOOC Research Institute Co. Ltd., Beijing 100028, China \\ Correspondence should be addressed to Zhijie Wei; weizhj5@cnooc.com.cn
}

Received 13 April 2021; Revised 12 May 2021; Accepted 7 July 2021; Published 29 July 2021

Academic Editor: Ondra Sracek

Copyright (c) 2021 Zhijie Wei et al. This is an open access article distributed under the Creative Commons Attribution License, which permits unrestricted use, distribution, and reproduction in any medium, provided the original work is properly cited.

\begin{abstract}
Low primary recovery factor and rapid production decline necessitates the proposal of enhanced oil recovery methods to mobilize the remaining oil resource of tight reservoirs, especially for oil-wet ones, and wettability alteration by injecting a chemical agent such as a surfactant is a promising option. A discrete-fracture-network-based mathematical model is developed with consideration of the displacement mechanisms and complicated physical-chemical phenomena during EOR by wettability alteration, and this model numerically solved by the fully implicit method. Simulation cases are conducted to investigate the production performance and key factors of cyclic injection of a surfactant. Cyclic injection can significantly improve the production of oil-wet tight reservoirs, and the ultimate recovery factor can be increased by 10 percent. The reason is that a surfactant can alter the wettability of a reservoir from oil wet to medium or even water wet, which triggers spontaneous imbibition and favors oil movement from a matrix into a fracture. Better EOR results can be achieved with decreasing oil viscosity, increasing matrix permeability, or decreasing fracture spacing. Cyclic surfactant injection is applicable to reservoirs with an oil viscosity of less than $7 \mathrm{mPa} \cdot \mathrm{s}$, a matrix permeability bigger than $0.01 \mathrm{mD}$, or a fracture spacing smaller than $150 \mathrm{~m}$. It is favorable for the wettability alteration method by maintaining capillary pressure and reducing residual oil saturation as much as possible.
\end{abstract}

\section{Introduction}

It is not feasible for tight reservoirs to achieve economic production by conventional methods. In general, artificial hydraulic fracturing and then depletion recovery are conducted. However, this method has disadvantages of rapid production decline and low recoverable reserves, and the ultimate recovery factor is usually only $5 \sim 15 \%$ [1-3], which shows great potential for enhanced oil recovery. As for water-wet reservoirs, elastic energy plays a major role in the early stage of development. The pressure of a fracture drops more quickly than that of a matrix, and oil flows from a matrix to a fracture. As the pressure difference decreases, the capillary pressure gradually becomes considerable due to the ultralow pore structure of the tight reservoir, and spontaneous imbibition gradually dominates the fluid flow $[4,5]$, which further improves oil and water exchange between the matrix and the fracture and achieves additional oil recovery in the matrix. However, it is not the case for oil-wet reser- voirs. Capillary pressure in this type of reservoir acts as a resistance force, which hinders further mass exchange between the matrix and the fracture and leads to poor oil mobilization in the matrix [6-9]. This is what motivated the investigation of the enhanced oil recovery method by wettability alteration. Meng et al. and $\mathrm{Xu}$ et al. conducted research on the injection of a chemical agent such as a surfactant into a reservoir to alter its wettability from oil wet to neutral or even to water wet, which triggers spontaneous imbibition and further mobilizes the remaining oil in a matrix; it also improves the oil production rate and the recovery factor and thus provides technical support for efficient development of a tight reservoir $[10,11]$.

At present, the related research usually adopts the laboratory experiment method [12-15]. As an important supplement and improvement, the numerical simulation method is proposed in this study to conduct research on the enhanced oil recovery by the wettability alteration method for tight reservoirs. The conventional numerical simulation 
method assumes the continuous distribution of a fracture, and generally has difficulty in capturing wettability alteration from oil wet to water wet [16-19]. Therefore, taking into full consideration the discrete and discontinuous distribution of a fracture in tight reservoir, the oil displacement mechanism by chemical injection, and its complex seepage law, a mathematical model of enhanced oil recovery based on wettability alteration and discrete-fracture network for tight reservoirs is developed.

\section{Mathematical Model of Enhanced Oil Recovery by Wettability Alteration}

In order to propose a mathematical model for enhanced oil recovery (EOR) of tight oil reservoirs by wettability alteration, the treatment of a complex discrete-fracture network and the characterization of wettability alteration are important. The pore system of a tight reservoir consists of a fracture and a matrix, especially after fracture treatment. The former provides the main fluid flow channel with the properties of big permeability and small porosity, while the latter provides the main storage space for oil with the properties of small permeability and big porosity. The dual-porosity dualpermeability model is generally utilized to describe the flow process in the formation $[20,21]$. The corresponding flow process can be described as follows: the fracture pressure drops rapidly as the development goes on, while the matrix pressure drops relatively slowly, which creates potential difference and oil migration from the matrix to the fracture, and then it flows into a wellbore via Darcy's flow. However, it is believed that this model has some limitations. Generally, a fracture is not uniformly distributed in the whole formation, but relatively dispersed and concentrated in some areas $[22,23]$. This is the conventional description method of the dual-porosity dual-permeability model, i.e., each grid is made up of a fracture and a matrix at the same time, which has difficulty in accurately capturing the real pore system of a formation, and increases unnecessary computational cost on the other hand. So, on the basis of the results of reservoir description, it can be divided into a matrix or a fracture according to its physical properties, and both are exclusive and do not overlap in the space. Each grid is a matrix or a fracture, and there is no possibility that both exist at the same time, which is not the case for the conventional dual-porosity dual-permeability model. The discrete-fracture-networkbased simulation method has a natural advantage in dealing with unstructured grids, which enables it to effectively describe the complicated outer boundary of a reservoir and the inner boundary between a fracture and a matrix; it is also numerically superior so that it can overcome the limitations of the dual-porosity model.

In addition, when a surfactant is injected into the oil-wet tight reservoirs, the wettability of the reservoirs is altered from oil wet to water wet due to the adsorption of the surfactant onto the rock, which triggers spontaneous imbibition of water into the matrix from the fracture under capillary pressure and then displaces oil in the matrix to the fracture [14, $15,19]$. On the other hand, the injected surfactant can greatly reduce the interfacial tension between oil and water phases, and increase the capillary number, as well as significantly reduce the residual oil saturation. Both cause the relative permeability curves of the oil and water phases to move to the right, and the magnitude and direction of capillary pressure change accordingly. Thus, the wetting alteration can be molded by modifying the relative permeability function, and the alteration degree depends on the surfactant concentration or adsorption. The governing equations consist of mass conservation equations, a conductivity equation, and a wettability alteration equation.

2.1. Mass Conservation Equations. As for enhanced oil recovery by wettability alteration using a chemical agent in tight oil reservoirs, four components, namely, water, oil, gas, and chemical agent need to be considered. Given the assumption that the mass exchange between the oil and water phases is ignored, and that the adsorption of the chemical agent onto the matrix, the gas dissolution in the oil phase, and source and sink terms are considered, then their mass conservation equations are as follows:

(1) Water

$$
\sum_{j} T_{j i} \frac{\rho_{\mathrm{w}} K_{\mathrm{rw}}}{\mu_{\mathrm{w}}}\left(\Phi_{j, \mathrm{w}}-\Phi_{i, \mathrm{w}}\right)-q_{\mathrm{w}, \mathrm{well}}=\int_{V_{i}} \frac{\partial}{\partial t}\left(\rho_{\mathrm{w}} \phi S_{\mathrm{w}}\right) \mathrm{d} V
$$

(2) Oil

$$
\sum_{j} T_{j i} \frac{\rho_{\mathrm{o}} K_{\mathrm{ro}}}{\mu_{\mathrm{o}}}\left(\Phi_{j, \mathrm{o}}-\Phi_{i, \mathrm{o}}\right)-q_{\mathrm{o}, \text { well }}=\int_{V_{i}} \frac{\partial}{\partial t}\left(\rho_{\mathrm{o}} \phi S_{\mathrm{o}}\right) \mathrm{d} V
$$

(3) Gas

$$
\begin{array}{r}
\sum_{j} T_{j i} \frac{\rho_{\mathrm{g}} K_{\mathrm{rg}}}{\mu_{\mathrm{g}}}\left(\Phi_{j, \mathrm{~g}}-\Phi_{i, \mathrm{~g}}\right)+\sum_{j} T_{j i} \frac{\rho_{\mathrm{o}} K_{\mathrm{ro}} R}{\mu_{\mathrm{o}}}\left(\Phi_{j, \mathrm{o}}-\Phi_{i, \mathrm{o}}\right) \\
-\left(q_{\mathrm{g}, \text { well }}+q_{\mathrm{o}, \text { well }} R\right)=\int_{V_{i}} \frac{\partial}{\partial t}\left(\rho_{\mathrm{g}} \phi S_{\mathrm{g}}+\rho_{\mathrm{o}} \phi S_{\mathrm{o}} R\right) \mathrm{d} V .
\end{array}
$$

(4) Surfactant

$$
\begin{gathered}
\sum_{j} T_{j i} \frac{\rho_{\mathrm{w}} K_{\mathrm{rw}} C_{\mathrm{s}}}{\mu_{\mathrm{w}}}\left(\Phi_{j, \mathrm{w}}-\Phi_{i, \mathrm{w}}\right)-q_{\mathrm{w}, \mathrm{well}} C_{\mathrm{s}} \\
=\int_{V_{i}} \frac{\partial}{\partial t}\left[\rho_{\mathrm{w}} \phi S_{\mathrm{w}} C_{\mathrm{s}}+\rho_{\mathrm{r}}(1-\phi) C_{\mathrm{s}}^{\mathrm{a}}\right] \mathrm{d} V .
\end{gathered}
$$

In the abovementioned mass conservation equations, $\Phi$ is the potential $(\mathrm{Pa}) ; T$ is the conductivity between grids $\left(\mathrm{m}^{3}\right) ; K_{r}$ is 
relative permeability; $\rho$ is density $\left(\mathrm{kg} / \mathrm{m}^{3}\right) ; \mu$ is viscosity (mPa.s); $q$ is a source or a $\operatorname{sink}(\mathrm{kg} / \mathrm{s}) ; \phi$ is porosity; $t$ is time (s); $S$ is saturation; $R$ is gas solubility $\left(\mathrm{m}^{3} / \mathrm{m}^{3}\right) ; C_{\mathrm{s}}^{\mathrm{a}}$ is the adsorption of a surfactant $(\mathrm{kg} / \mathrm{kg}) ; C_{\mathrm{s}}$ is the concentration of a surfactant $(\mathrm{mg} / \mathrm{L}) ; \partial$ is the partial differential operator; subscripts $\mathrm{w}, \mathrm{o}$, and $\mathrm{g}$ are water, oil, and gas phases, respectively; $s$ is the surfactant component; well is an injector and a producer; $i$ and $j$ are block numbers; the superscript a is the adsorbed state.

2.2. Conductivity Equation of Discrete Fracture Network Model. As for the discrete-fracture-network model, it is very important to calculate the conductivity between matrix grids, between fracture grids, and between matrix and fracture grids. The calculation formula is as follows.

\subsubsection{Matrix-Matrix Grid Conductivity.}

$$
\begin{gathered}
T_{i j, \mathrm{~m}}=\frac{\alpha_{i, \mathrm{~m}} \alpha_{j, \mathrm{~m}}}{\alpha_{i, \mathrm{~m}}+\alpha_{j, \mathrm{~m}}}, \\
\alpha_{i, \mathrm{~m}}=\frac{K_{i, \mathrm{~m}} A_{i j, \mathrm{~m}}}{d_{i, \mathrm{~m}}} \vec{\tau}_{i j, \mathrm{~m}} \cdot \vec{\eta}_{i j, \mathrm{~m}},
\end{gathered}
$$

where $\alpha$ is transmissibility $\left(\mathrm{m}^{3}\right) ; K$ is permeability $(\mathrm{mD}) ; A$ is the contact surface area of adjacent grids $\left(\mathrm{m}^{2}\right) ; d$ is the distance between the gravity center of the grid and the center of the contact surface (m); $\vec{\tau}$ is the unit normal vector of the contact surface; $\vec{\eta}$ is the unit vector from the center of the contact surface to the gravity center of the matrix; subscript $m$ denotes the matrix.

\subsubsection{Fracture-Fracture Grid Conductivity.}

$$
\begin{gathered}
T_{i j, \mathrm{f}}=\frac{\alpha_{i, \mathrm{f}} \alpha_{j, \mathrm{f}}}{\alpha_{i, \mathrm{f}}+\alpha_{j, \mathrm{f}}}, \\
\alpha_{i, \mathrm{f}}=\frac{K_{i, \mathrm{f}} A_{i j, \mathrm{f}}}{d_{i, \mathrm{f}}} \vec{\tau}_{i j, \mathrm{f}} \cdot \vec{\eta}_{i j, \mathrm{f}},
\end{gathered}
$$

where the subscript $\mathrm{f}$ denotes fracture.

\subsubsection{Matrix-Fracture Grid Transmissibility.}

$$
\begin{gathered}
T_{i j, \mathrm{mf}}=\frac{\alpha_{i, \mathrm{f}} \alpha_{j, \mathrm{~m}}}{\alpha_{i, \mathrm{f}}+\alpha_{j, \mathrm{~m}}}, \\
\alpha_{i, \mathrm{f}}=\frac{K_{i, \mathrm{f}} A_{i j, \mathrm{mf}}}{d_{i, \mathrm{f}}} \vec{\tau}_{i j, \mathrm{mf}} \cdot \vec{\eta}_{i j, \mathrm{mf}}, \\
\alpha_{j, \mathrm{~m}}=\frac{K_{j, \mathrm{~m}} A_{i j, \mathrm{mf}}}{d_{j, \mathrm{~m}}} \vec{\tau}_{i j, \mathrm{mf}} \cdot \vec{\eta}_{i j, \mathrm{mf}} .
\end{gathered}
$$

In fact, because of the fact that fracture permeability is much bigger than that of the matrix, and its size is far smaller than that of the matrix, we thus have $\alpha_{i, \mathrm{f}} \gg \alpha_{j, \mathrm{~m}}$, then $T_{i j, \mathrm{mf}} \approx \alpha_{j, \mathrm{~m}}$.

2.3. Wettability Alteration Equations. Wettability alteration can be described by modifying the relative permeability func- tion, and the alteration degree depends on the surfactant concentration in water and its adsorption amount onto the matrix. Two sets of relative permeability curves are introduced: one represents the original reservoir wettability state corresponding to zero surfactant concentration, and the other represents the ultimate state when its wettability is completely reversed corresponding to maximum surfactant concentration. Then, the relative permeability curves at a certain surfactant concentration can be written as the weighted average of the two conditions.

The oil-water relative permeability and capillary pressure at a certain concentration of a surfactant can be expressed as follows:

$$
\begin{gathered}
K_{\mathrm{r}}=\lambda_{\mathrm{kr}} \cdot K_{\mathrm{r}}^{\mathrm{ow}}+\left(1-\lambda_{\mathrm{kr}}\right) \cdot K_{\mathrm{r}}^{\mathrm{ww}} \\
\lambda_{\mathrm{kr}}=\lambda_{\mathrm{kr}}\left(C_{\mathrm{s}}^{\mathrm{a}}\right), \\
p_{\mathrm{c}}=\lambda_{\mathrm{pc}} \cdot p_{\mathrm{c}}^{\mathrm{ow}} \frac{\sigma\left(C_{\mathrm{s}}\right)}{\sigma\left(C_{\mathrm{s}}=0\right)}+\left(1-\lambda_{\mathrm{pc}}\right) \cdot p_{\mathrm{c}}^{\mathrm{ww}} \frac{\sigma\left(C_{\mathrm{s}}\right)}{\sigma\left(C_{\mathrm{s}}=\infty\right)}, \\
\lambda_{\mathrm{pc}}=\lambda_{\mathrm{pc}}\left(C_{\mathrm{s}}^{\mathrm{a}}\right),
\end{gathered}
$$

where $\lambda_{\mathrm{kr}}$, and $\lambda_{\mathrm{pc}}$ are the weight of relative permeability and capillary pressure respectability when the matrix adsorbs a certain amount of the surfactant; $p_{c}$ is capillary pressure $(\mathrm{Pa}) ; \sigma\left(C_{\mathrm{s}}\right)$ is the interfacial tension between the oil and water phases at a certain concentration of the surfactant $(\mathrm{N} / \mathrm{m}) ; \sigma\left(C_{\mathrm{s}}=0\right)$ is the interfacial tension at the initial reservoir condition $(\mathrm{N} / \mathrm{m}) ; \sigma\left(C_{\mathrm{s}}=\infty\right)$ is the interfacial tension at the ultimate state $(\mathrm{N} / \mathrm{m})$; the superscripts ow and ww denote the original wettability and the ultimate wettability when it is a complete turnaround. The relationship of surfactant adsorption $C_{\mathrm{s}}^{\mathrm{a}}$ and its concentration $C_{\mathrm{s}}$ generally obeys the Langmuir type curves:

$$
C_{\mathrm{s}}^{\mathrm{a}}=\frac{a C_{\mathrm{s}}}{b+C_{\mathrm{s}}},
$$

where $a$ and $b$ are Langmuir adsorption constants with units $\mathrm{kg} / \mathrm{kg}$ and $\mathrm{mg} / \mathrm{L}$.

The relative permeability curves and capillary pressure can be described as the following exponential equations:

$$
\begin{aligned}
K_{\mathrm{ro}} & =K_{\mathrm{ro}, \max }\left(\frac{S_{\mathrm{o}}-S_{\mathrm{or}}}{1-S_{\mathrm{or}}-S_{\mathrm{wi}}}\right)^{\eta_{1}}, \\
K_{\mathrm{rw}} & =K_{\mathrm{rw}, \max }\left(\frac{S_{\mathrm{w}}-S_{\mathrm{wi}}}{1-S_{\mathrm{or}}-S_{\mathrm{wi}}}\right)^{\eta_{2}}, \\
p_{\mathrm{c}} & =p_{\mathrm{c}, \max }\left(\frac{S_{\mathrm{o}}-S_{\mathrm{or}}}{1-S_{\mathrm{or}}-S_{\mathrm{wi}}}\right)^{\eta_{3}},
\end{aligned}
$$

where $S_{\text {or }}$ and $S_{\mathrm{wi}}$ are residual saturation to oil and water; $K_{\text {ro,max }}$ and $K_{\text {rw,max }}$ are the relative permeability endpoints to oil and water; $\eta_{1}$ and $\eta_{2}$ are exponents of relative permeability to oil and water; $K_{\text {rw,max }}$ is the capillary pressure 
endpoint; $\eta_{3}$ is the exponent of relative permeability to oil and water.

Accordingly, the irreducible water saturation and residual oil saturation at a certain surfactant concentration can be written as follows

$$
\begin{gathered}
S_{\mathrm{r}}=\lambda_{\mathrm{sr}} \cdot S_{\mathrm{r}}^{\mathrm{ow}}+\left(1-\lambda_{\mathrm{sr}}\right) \cdot S_{\mathrm{r}}^{\mathrm{ww}}, \\
\lambda_{\mathrm{sr}}=\lambda_{\mathrm{sr}}\left(N_{\mathrm{c}}\right), \\
N_{\mathrm{c}}=\frac{|K \nabla \Phi|}{\sigma\left(C_{\mathrm{s}}\right)},
\end{gathered}
$$

where $\lambda_{\text {sr }}$ is the weight number of irreducible water saturation or residual oil at a certain concentration of the surfactant in water; $N_{c}$ is the capillary number; $\nabla$ is the gradient operator.

2.4. Numerical Solution. To sum up, the discrete-fracturenetwork-based mathematical model of enhanced oil recovery by wettability alteration in a tight oil reservoir is proposed and the governing equations are equation (1), equation (2), equation (3), and equation (4). The primary unknowns include water pressure, $\boldsymbol{p}_{\mathrm{w}}$; water saturation, $\boldsymbol{S}_{\mathrm{w}}$; oil saturation, $S_{\mathbf{o}}$; and surfactant concentration, $C_{s}$. The fully implicit finite volume method is adopted to compute for the numerical difference:

$$
\sum_{j} T_{j i} \frac{\rho_{l} K_{\mathrm{rl}}}{\mu_{l}}\left(\Phi_{j, l}-\Phi_{i, l}\right)-q_{1, \mathrm{well}}=\int_{V_{i}} \frac{\partial}{\partial t}\left(\rho_{l} \phi S_{l}\right) \mathrm{d} V .
$$

We expand equation (12), and we obtain

$$
\begin{gathered}
\sum_{j} T_{j i}^{N+1}\left(\frac{\rho_{l} K_{\mathrm{r} l}}{\mu_{l}}\right)^{N+1} \Phi_{j, l}^{N+1}-\sum_{j} T_{j i}^{N+1}\left(\frac{\rho_{l} K_{\mathrm{rl}}}{\mu_{l}}\right)^{N+1} \Phi_{i, l}^{N+1} \\
-q_{l, \text { well }}^{N+1}=\frac{\left(\rho_{l} \phi S_{l}\right)_{i}^{N+1}-\left(\rho_{l} \phi S_{l}\right)_{i}^{N}}{\Delta t} V_{i} \\
V_{i}=\Delta x_{i} \Delta y_{i} \Delta z_{i} .
\end{gathered}
$$

The Newton-Raphson iterative approach and fully implicit method is utilized to solve the above governing equations, and the corresponding numerical solver is developed. The primary unknowns (i.e., $\boldsymbol{p}, \boldsymbol{S}_{\mathrm{w}}, \boldsymbol{S}_{\mathrm{o}}$, and $\boldsymbol{C}_{\mathrm{s}}$ ) and mobility are solved simultaneously, then forwarded to the next time step. In addition, an upstream scheme is applied to determine the mobility to improve its computational stability.

2.5. Model Verification. A history matching of the experiment results of spontaneous imbibition of oil-wet tight cores is carried out to verify the accuracy of the mathematical model. One saturated tight core with a length, width, and height of $3.4 \mathrm{~cm}, 3.4 \mathrm{~cm}$, and $7.6 \mathrm{~cm}$ is placed into the surfactant solution with a concentration of $3000 \mathrm{mg} / \mathrm{L}$, and oil recovery from the core is recorded. The relationship of recovery factor to time is obtained and shown in Figure 1. The core has a matrix permeability of $0.1 \mathrm{mD}$, a porosity of 0.12 , an oil viscosity of $3.0 \mathrm{mPa} \cdot \mathrm{s}$, and initial oil and water saturation levels

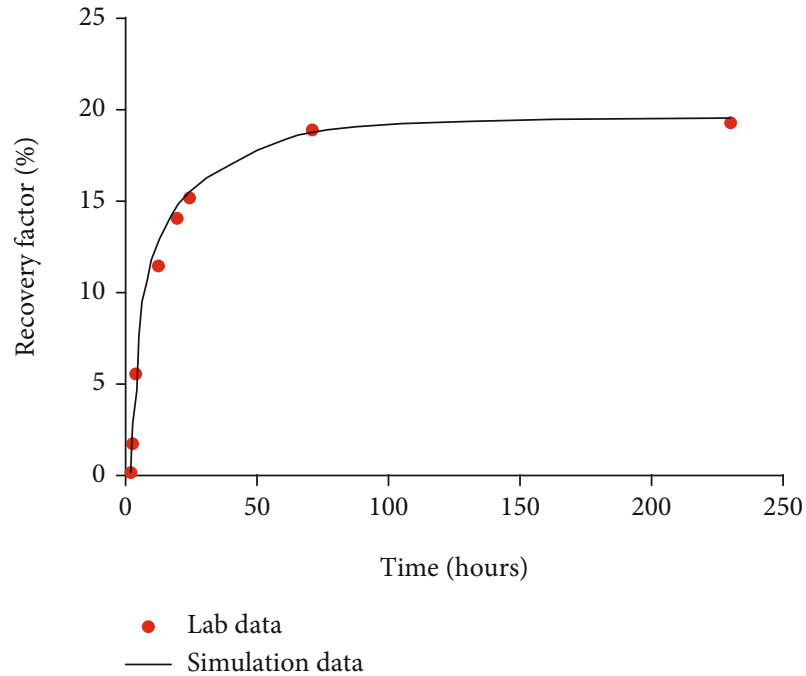

Figure 1: History matching results of the spontaneous imbibition experiment for an oil-wet tight core.

TABLE 1: Characteristic parameters of relative permeability curves.

\begin{tabular}{lcccc}
\hline \multirow{2}{*}{ Parameters } & \multicolumn{2}{c}{ Oil-wet core } & \multicolumn{2}{c}{ Water-wet core } \\
& Oil & Water & Oil & Water \\
\hline Residual saturation & 0.38 & 0.32 & 0.38 & 0.32 \\
Relative permeability endpoints & 0.59 & 0.23 & 0.59 & 0.23 \\
Relative permeability exponents & 3.3 & 2.90 & 2.00 & 2.00 \\
Capillary pressure endpoints & \multicolumn{2}{c}{-5} & & 10 \\
Capillary pressure exponents & \multicolumn{2}{c}{2} & & 2 \\
\hline
\end{tabular}

of 0.68 and 0.32 , respectively. The history matching parameters, i.e., characteristic parameters of relative permeability and capillary pressure, are shown in Table 1. Figure 1 shows that the simulation results have a good agreement with the lab data, and the fitting coefficient is more than $90 \%$, which verifies the accuracy and reliability of the mathematical model proposed in this study.

\section{Enhanced Oil Recovery by Wettability Alteration Method for Tight Reservoirs}

The mathematical model proposed in this study is applied to investigate enhanced oil recovery of the wettability alteration method by cyclic surfactant injection for tight oil-wet reservoirs. Simulation of a horizontal fracturing situation is conducted, and basic parameters include a fracture spacing of $150 \mathrm{~m}$, a control area size for one single fracture of $150 \mathrm{~m} \times$ $150 \mathrm{~m} \times 20 \mathrm{~m}$, a matrix permeability of $0.1 \mathrm{mD}$, a porosity of 0.12 , a fracture permeability of $100000 \mathrm{mD}$, an oil viscosity of $5.0 \mathrm{mPa} \cdot \mathrm{s}$, initial water and oil saturation levels of 0.23 and 0.77 , and a residual oil saturation of 0.35 ; its initial wettability is oil wet. The method of cyclic surfactant injection is utilized; that is, it firstly depletes for 5 months, then it is transferred for injection with a surfactant solution at $3000 \mathrm{mg} / \mathrm{L}$ with a duration of 2 months and a shut-in for 10 days, and finally, it is set for reproduction for 7 months. The procedures are repeated for 7 cycles. 


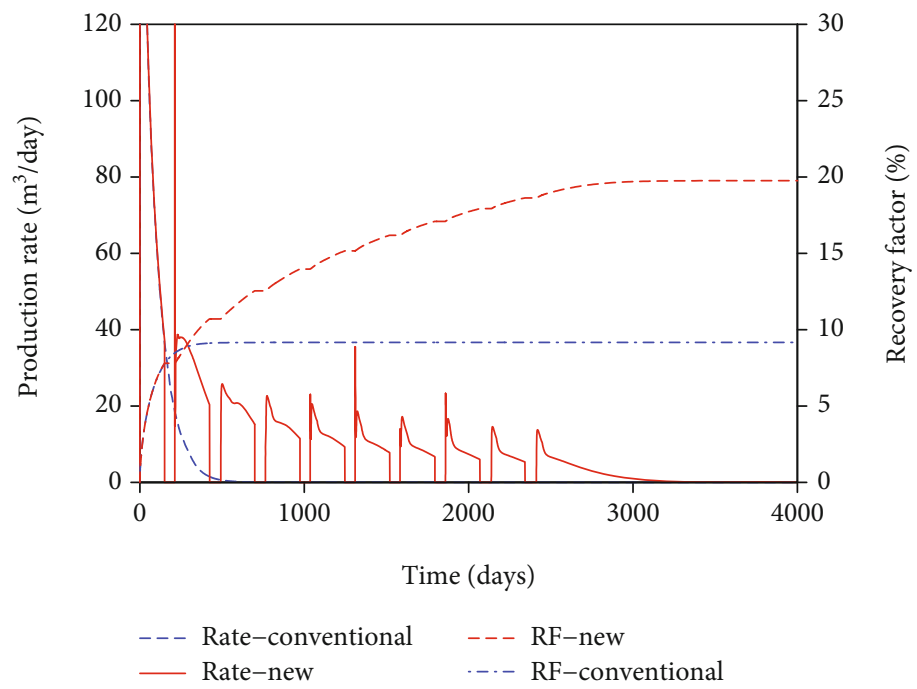

Figure 2: Production curves of oil-wet tight reservoirs with conventional depletion and the new cyclic surfactant injection method.

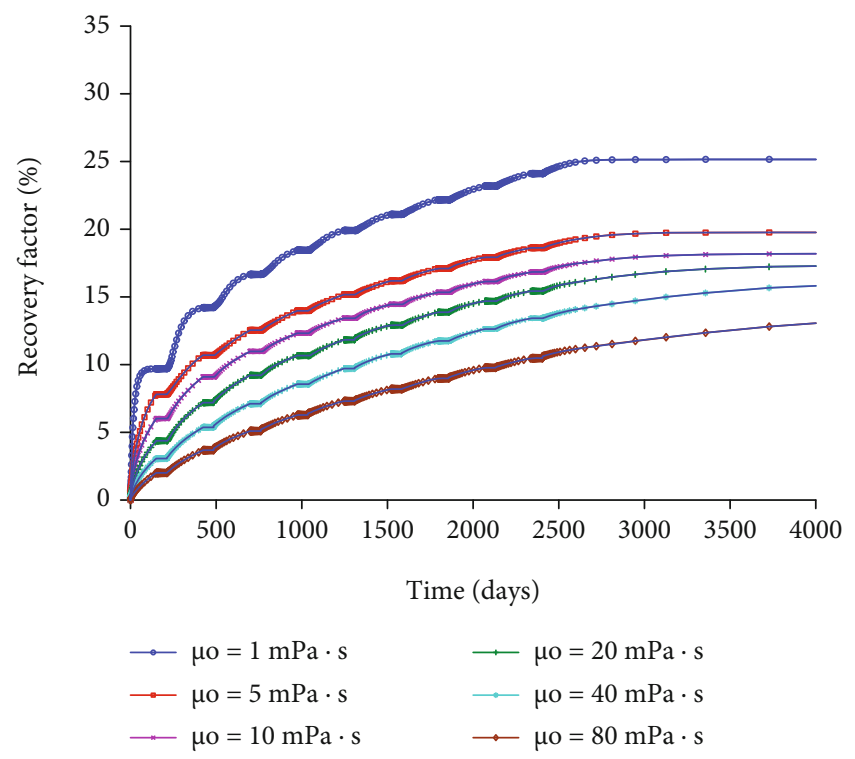

Figure 3: Production curves of reservoirs with different oil viscosities by cyclic surfactant injection.

3.1. Analysis of Enhanced Oil Recovery by Cyclic Surfactant Injection. The blue and red lines in Figure 2 indicate the oil production rate and recovery factor of an oil-wet tight reservoir under the conventional depletion method and cyclic surfactant injection, where the "new" and "conventional" in Figure 2 indicate the cyclic surfactant injection and depletion method, respectively. As for the depletion method, the production rate decays fast and there is almost no considerable production after one year, and the ultimate recovery factor is only $9.1 \%$. However, the new cyclic surfactant injection can significantly improve oil production and extend the effective production duration, and the final recovery factor can reach $19.7 \%$, which is 10 percent higher than depletion recovery, while it is only 5.2 percentage higher by the cyclic water injection method (without surfactant). The reason is

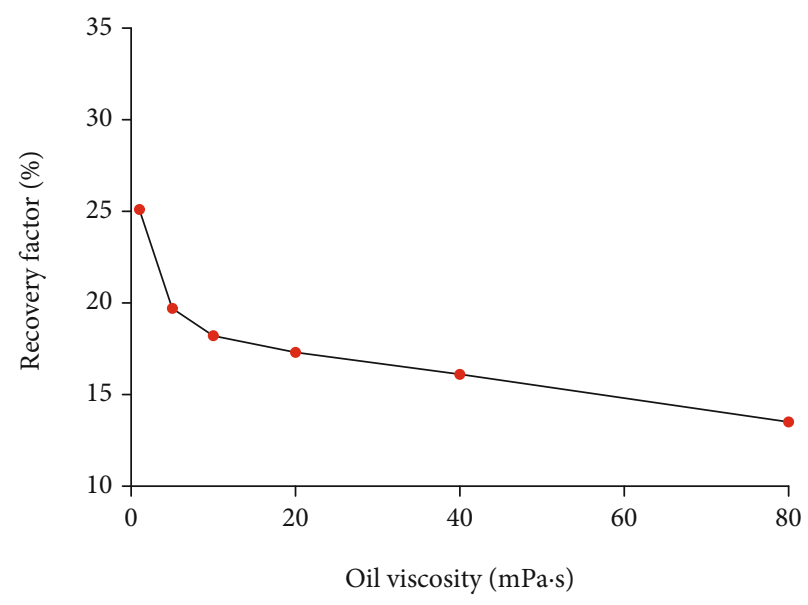

Figure 4: Ultimate recovery factors of reservoirs with different oil viscosities by cyclic surfactant injection.

that capillary pressure at the original oil-wet state prevents mass exchange between the fracture and the matrix, but as rock wettability changes into water wet after adding the surfactant, it is converted into a driving force and then induces spontaneous imbibition, which pulls water into the matrix from the fracture and meanwhile it pushes oil into the fracture from the matrix, so as to further improve oil recovery.

\subsection{Sensitivity Analysis}

3.2.1. Oil Viscosity. Figure 3 shows the production curves of reservoirs with different oil viscosities by cyclic surfactant injection. As oil viscosity increases, the fluid-flow capacity decreases and the imbibition strength between a matrix and a fracture decreases, resulting in a reduction in the oil production rate and the ultimate recovery factor. This finding indicates that the requirement of surfactant performance increases as oil viscosity increases for oil-wet reservoirs. The relationship between ultimate recovery factor and oil viscosity is shown in Figure 4 . Oil viscosity has an inflection 


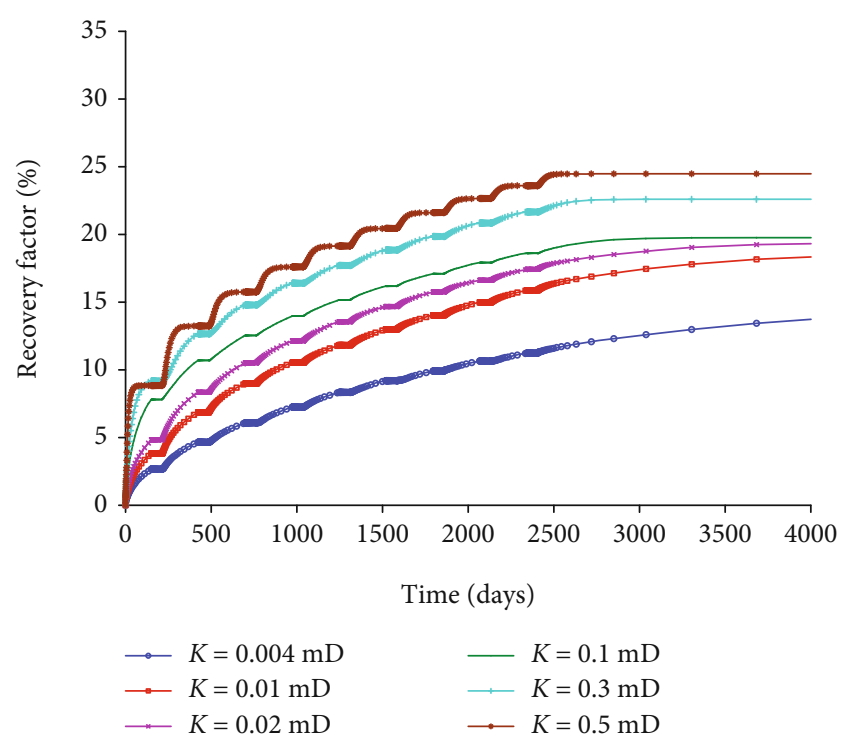

FiguRe 5: Production curves of reservoirs with different matrix permeabilities by cyclic surfactant injection.

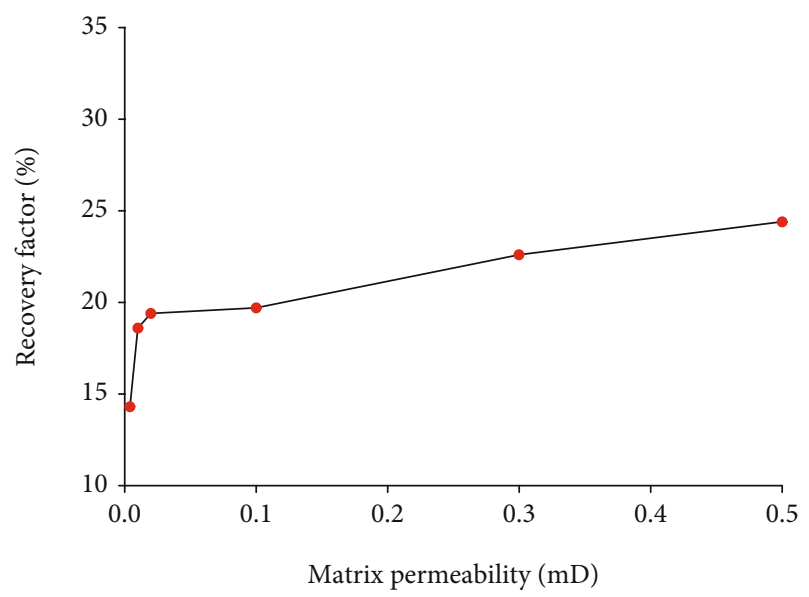

FIGURE 6: Ultimate recovery factors of reservoirs with different matrix permeabilities by cyclic surfactant injection.

point: the final recovery factor decreases rapidly as oil viscosity increases when it is lower than $7.0 \mathrm{mPa} \cdot \mathrm{s}$, while it decreases mildly and almost linearly when it is bigger than this. The simulation results show that the wettability alteration method by cyclic surfactant injection is more effective for tight reservoirs with an oil viscosity less than $7 \mathrm{mPa} \cdot \mathrm{s}$.

3.2.2. Matrix Permeability. Figure 5 shows the production curves of reservoirs with different matrix permeabilities by cyclic surfactant injection. As permeability increases, imbibition strength increases, oil recovery rate increases, and the ultimate recovery factor also increases. The relationship between the ultimate recovery factor and matrix permeability is shown in Figure 6. There is an inflection point in the permeability. The final recovery factor increases rapidly as permeability increases when it is lower than $0.1 \mathrm{mD}$, while it increases mildly when it is bigger than this. There is only a little difference in the recovery factor with a permeability range

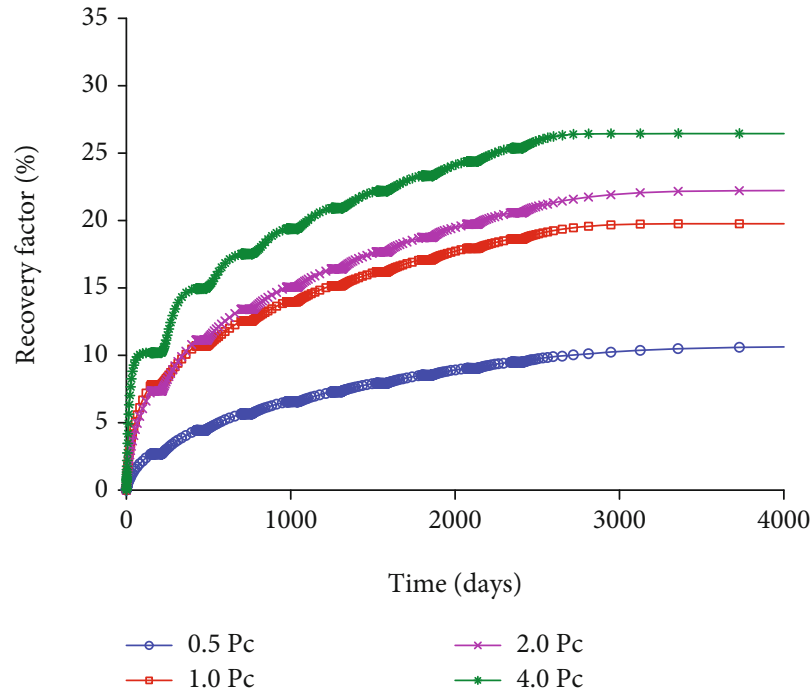

FIgURe 7: Production curves of reservoirs with different capillary pressure multipliers by cyclic surfactant injection.

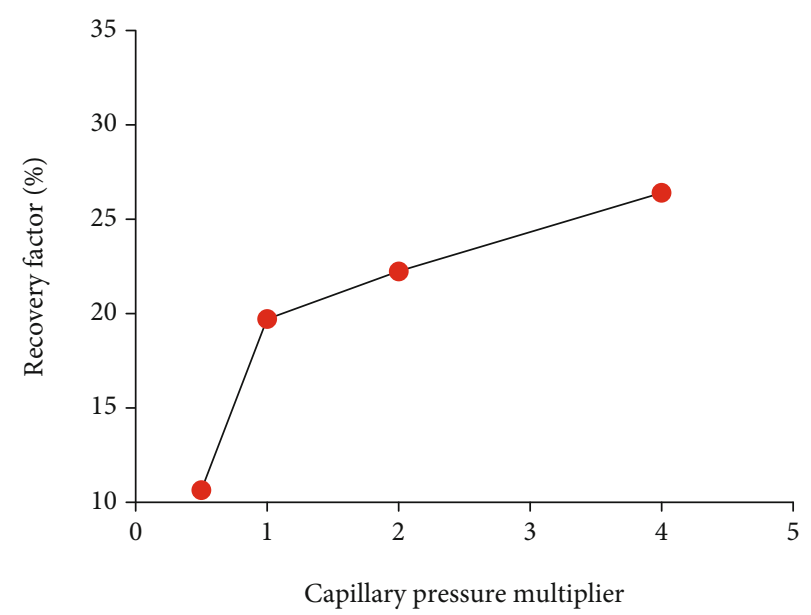

FIGURE 8: Ultimate recovery factors of reservoirs with different capillary pressure multipliers by cyclic surfactant injection.

between 0.1 and $1.0 \mathrm{mD}$. The simulation results show that the wettability alteration method by cyclic surfactant injection can achieve better EOR results for reservoirs with matrix permeability bigger than $0.01 \mathrm{mD}$.

3.2.3. Capillary Pressure. Wettability alteration is the key to enhancing oil recovery of tight reservoirs by surfactant injection. As an important aspect, capillary pressure alteration is evaluated by modifying the capillary pressure endpoints at the ultimate state; then, the capillary pressure multiplier is set to $0.5,1.0,2.0$, and 4.0 , and the corresponding capillary pressure is $5,10,20$, and $40 \mathrm{kPa}$, respectively. Figure 7 shows the production curves of reservoirs with different capillary pressure multipliers by cyclic surfactant injection. As the multiplier increases, capillary pressure as the driving force and imbibition strength increases, and the oil production rate and the ultimate recovery factor also increases. The relationship between the ultimate recovery factor and the capillary 


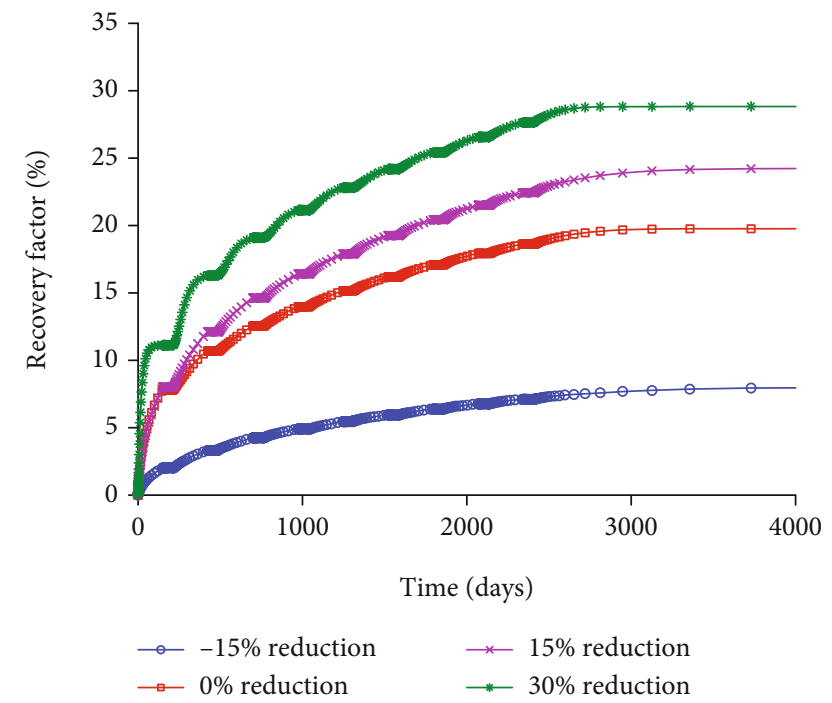

Figure 9: Production curves of reservoirs with different Sor reduction values by cyclic surfactant injection.

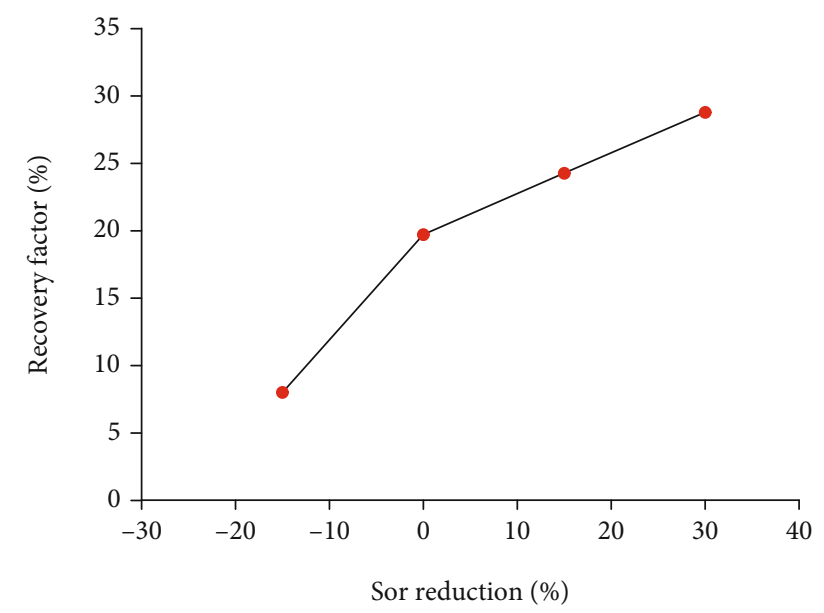

FIGURE 10: Ultimate recovery factors of reservoirs with different Sor reduction values by cyclic surfactant injection.

pressure multiplier is shown in Figure 8. There is an inflection point, i.e., the final recovery factor increases rapidly as the multiplier increases when it is lower than 1.0, while it increases almost linearly when it is bigger. The simulation results show that the wettability alteration method by cyclic surfactant injection can achieve better EOR results for reservoirs with capillary pressure multipliers bigger than 1.0.

3.2.4. Residual Oil Saturation Reduction. Wettability alteration is key to enhancing oil recovery of tight reservoirs by surfactant injection. As another important aspect, residual oil saturation reduction is evaluated by modifying its value at the ultimate state by $-15 \%, 0 \%, 15 \%$, and $30 \%$, and it is set to $0.447,0.380,0.330$, and 0.292 , respectively. Figure 9 shows the production curves of reservoirs with different Sor reduction values by cyclic surfactant injection. As reduction increases, imbibition strength increases, and the oil production rate and the ultimate recovery factor also increases.

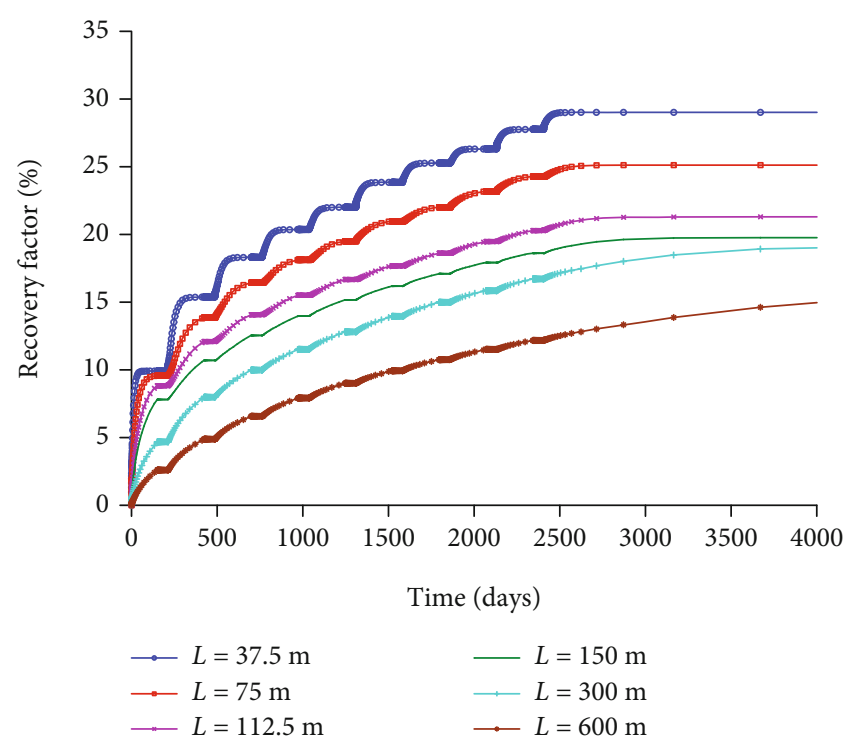

FIgURE 11: Production curves of reservoirs with different fracture spacing distances by cyclic surfactant injection.

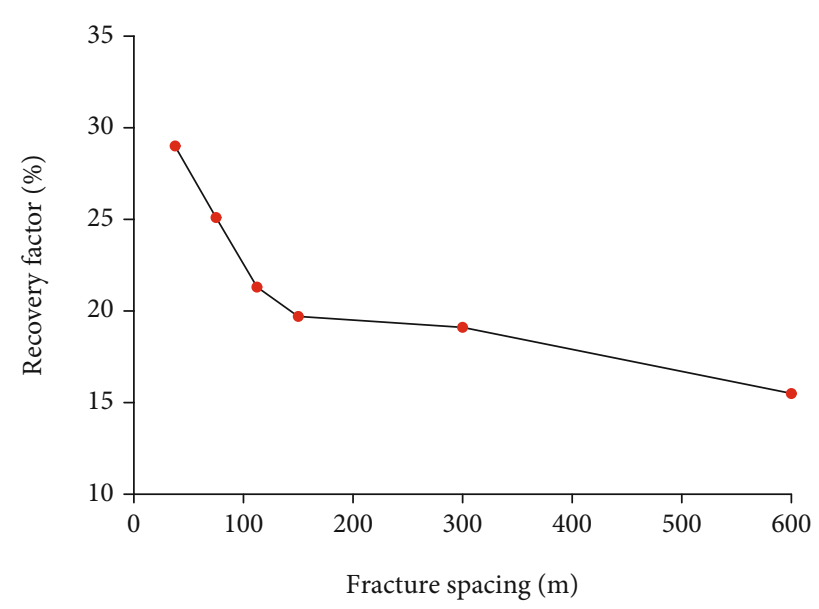

FIGURE 12: Ultimate recovery factors of reservoirs with different fracture spacing distances by cyclic surfactant injection.

The relationship between the ultimate recovery factor and Sor reduction is shown in Figure 10. There is an inflection point, i.e., the final recovery factor increases rapidly as reduction increases when it is lower than $0.0 \%$, while it increases almost linearly when it is bigger. The simulation results show that the wettability alteration method by cyclic surfactant injection can achieve better EOR results for reservoirs with Sor reduction bigger than $0.0 \%$.

3.2.5. Fracture Spacing. Figure 11 shows the production curves of reservoirs with different fracture spacing distances by cyclic surfactant injection. As fracture spacing decreases, the imbibition strength increases and the oil recovery result becomes better. The relationship between ultimate recovery factor and fracture spacing is shown in Figure 12. There is an inflection point in fracture spacing. The final recovery factor decreases rapidly as fracture spacing increases when it is lower than $150 \mathrm{~m}$, while it decreases mildly when it is bigger 


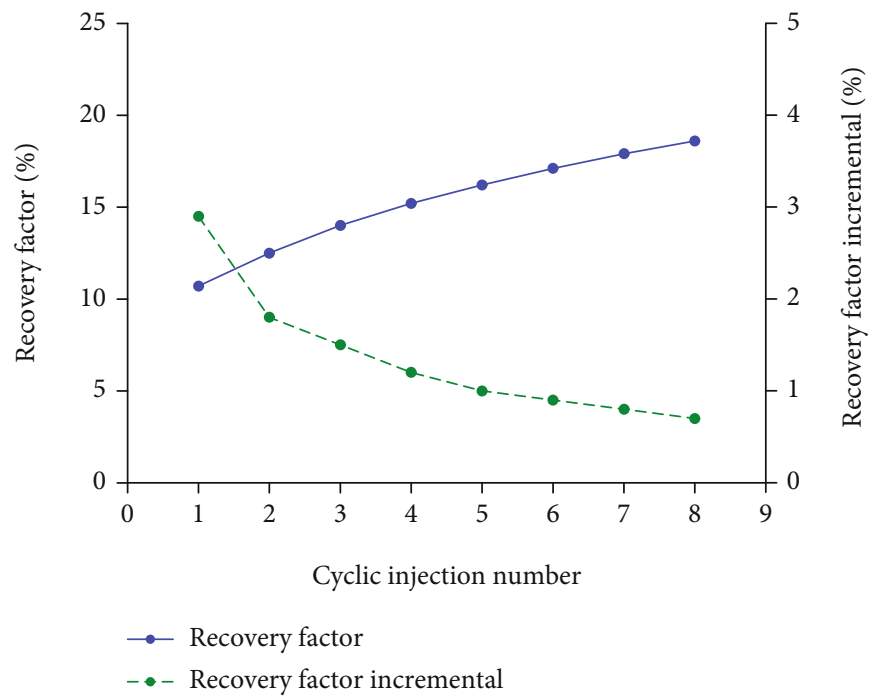

FIGURE 13: Recovery factors and recovery factor incremental with different cyclic surfactant injection numbers.

than this. There is only little difference in the recovery factor with fracture spacing ranging between $150 \mathrm{~m}$ and $300 \mathrm{~m}$. The simulation results show that the wettability alteration method by cyclic surfactant injection can achieve better EOR results for reservoirs with fracture spacing distances smaller than $150 \mathrm{~m}$.

3.2.6. Cyclic Surfactant Injection Number. Recovery factors and recovery factor incremental of each cycle with different cyclic surfactant injection numbers are shown in Figure 13. As the cycle increases, the recovery factor increases slowly and recovery factor incremental decreases.

\section{Conclusions}

(1) A discrete-fracture-network-based mathematical model is proposed for EOR with the wettability alteration method by surfactant injection in tight reservoirs, which can not only capture the EOR mechanisms and complicate physical-chemical phenomena but also effectively and precisely describe a fracture network. Its numerical solver is developed with a fully implicit method and has advantages of computational stability and efficiency

(2) Cyclic surfactant injection can significantly improve the production performance of oil-wet tight reservoirs, and the ultimate recovery factor can be increased by 10 percent. Surfactant injection can alter the wettability of a reservoir even from oil wet to medium or water wet, which triggers spontaneous imbibition and favors oil movement from the matrix to a fracture and improves production performance

(3) Cyclic surfactant injection can achieve better EOR results with decreasing oil viscosity, increasing matrix permeability, or decreasing fracture spacing. It is applicable when the oil viscosity is less than $7 \mathrm{mPa} \cdot \mathrm{s}$, the matrix permeability is bigger than $0.01 \mathrm{mD}$, or the fracture spacing is smaller than $150 \mathrm{~m}$. It is favorable for the wettability alteration method by maintaining capillary pressure and reducing residual oil saturation as much as possible

\section{Data Availability}

All data are included in the paper.

\section{Conflicts of Interest}

The authors declare that they have no conflicts of interest.

\section{Acknowledgments}

The authors are grateful for the financial support from the State Major Science and Technology Special Project of China during the 13th Five-Year Plan (Grant No. 2016ZX05025003) and the National Natural Science Foundation of China (Grant No. 52074347).

\section{References}

[1] M. Dawson, D. Nguyen, N. Champion, and H. Li, "Designing an optimized surfactant flood in the Bakken," in The Proceedings of the SPE/CSUR Unconventional Resources Conference, Richardson: SPE Society, Calgary, Alberta, Canada, 2015.

[2] H. Li, M. Dawson, and D. Standnes, "Multi-scale rock characterization and modeling for surfactant EOR in the Bakken," in The Proceedings of the SPE/CSUR Unconventional Resources Conference, Richardson: SPE Society, Calgary, Alberta, Canada, 2015.

[3] W. Tian, K. Wu, Y. Gao, Z. Chen, Y. Gao, and J. Li, “A critical review of enhanced oil recovery by imbibition: theory and practice," Energy \& Fuels, vol. 35, no. 7, pp. 5643-5670, 2021.

[4] E. Brownscombe and A. Dyes, "Water-imbibition displacement, a possibility for the Spraberry," Drilling and Production Practice, vol. 7, no. 5, pp. 383-390, 1952. 
[5] C. Mattax and J. Kyte, "Imbibition oil recovery from fractured water-drive reservoir," SPE Journal, vol. 2, no. 2, pp. 177-184, 1962.

[6] W. Zhu, J. Yan, Z. Ming et al., "Spontaneous imbibition mechanism of flow through porous media and waterflooding in low permeability fractured sandstone reservoir," Acta Petrolei Sinica, vol. 23, no. 6, pp. 56-59, 2002.

[7] G. Penny, A. Zelenev, W. Long, N. Lett, and J. Crafton, "Laboratory and field evaluation of proppants and surfactants used in fracturing of hydrocarbon rich gas reservoirs," in The Proceedings of the SPE Annual Technical Conference and Exhibition, Richardson: SPE Society, San Antonio, Texas, USA, 2012.

[8] J. O. Alvarez, A. Neog, A. Jais, and D. S. Schechter, "Impact of surfactants for wettability alteration in stimulation fluids and the potential for surfactant EOR in unconventional liquid reservoirs," in The Proceedings of the SPE Unconventional Resources Conference, Richardson: SPE Society, Woodlands, Texas, USA, 2014.

[9] J. Xu and L. Ma, "Spontaneous imbibition in fractured low permeability reservoir," Petroleum Geology and Recovery Efficiency, vol. 22, no. 3, pp. 111-114, 2015.

[10] Z. Meng, S. Yang, Y. Cui et al., "Enhancement of the imbibition recovery by surfactants in tight oil reservoirs," Petroleum Science, vol. 15, no. 4, pp. 783-793, 2018.

[11] G. Xu, Y. Han, Y. Jiang, Y. Shi, M. Wang, and X. H. Zeng, "Reducing residual oil saturation: underlying mechanism of imbibition in oil recovery enhancement of tight reservoir," SPE Journal, vol. 97, no. 7, pp. 1-12, 2021.

[12] M. Mianmo, G. Hongkui, J. Wenming, G. Qichao, and R. Kai, "NMR study on shale spontaneous imbibition," Special Oil and Gas Reservoir, vol. 22, no. 5, pp. 137-140, 2015.

[13] X. Wang, X. Peng, S. Zhang, Z. du, and F. Zeng, "Characteristics of oil distributions in forced and spontaneous imbibition of tight oil reservoir," Fuel, vol. 224, pp. 280-288, 2018.

[14] X. Wang, Z. Yang, and L. Xuewei, "Physical simulation experiment investigation on large scale model using countercurrent imbibition in tight oil reservoirs," Science Technology and Engineering, vol. 18, no. 8, pp. 43-48, 2018.

[15] S. Hao, L. Zhengdong, Z. Diqiu, L. Junchao, J. Binshan, and Z. Zhang, "Volume fracturing parameters optimization of horizontal well in tight reservoir," Lithologic Reservoirs, vol. 30, no. 4, pp. 140-148, 2018.

[16] R. Basabdatta, T. Tsotsis, and K. Jessen, “An experimental and numerical investigation of spontaneous imbibition in gas shales," Journal of Petroleum Science and Engineering, vol. 111, no. 2, pp. 87-97, 2013.

[17] F. Yingkun, L. Zhiping, L. Fengpeng, Y. Sen, and Y. Baosong, "A simulation research on evaluation of development in tight oil reservoirs by near-miscible gas injection," Science Technology and Engineering, vol. 14, no. 4, pp. 37-42, 2014.

[18] Z. Zhou, T. Hoffman, D. Bearinger, X. Li, and H. Abass, "Experimental and numerical study on spontaneous imbibition of fracturing fluids in the Horn river shale gas formation," SPE Drilling \& Completion, vol. 31, no. 3, pp. 168-177, 2016.

[19] S. Haijing, W. Yungang, D. Yong, L. Hualin, and G. Hui, “A flow numerical simulation technology on gas-water two phase in tight gas reservoirs with abnormally high pressure," Science Technology and Engineering, vol. 17, no. 24, pp. 204-208, 2017.
[20] J. Warren and P. Root, "The behavior of naturally fractured reservoirs," SPE Journal, vol. 3, no. 3, pp. 245-255, 1963.

[21] F. Sonier, P. Souillard, and F. T. Blaskovich, "Numerical simulation of naturally fractured reservoirs," SPE Reservoir Evaluation \& Engineering, vol. 3, no. 4, pp. 1114-1122, 1988.

[22] W. Zhijie, K. Xiaodong, L. Yuyang, and Y. Guang, "Key impact factors of spontaneous imbibition EOR in tight oil reservoirs," Journal of Chongqing University of Science and Technology (Natural Sciences Edition), vol. 20, no. 2, pp. 39-43, 2018.

[23] A. Bagherinezhad and M. R. Pishvaie, "A new approach to countercurrent spontaneous imbibition simulation using Green element method," Journal of Petroleum Science \& Engineering, vol. 119, no. 5, pp. 163-168, 2014. 